\title{
A MOTIVAÇÃO PARA AS PRIMEIRAS PERIPÉCIAS NA GINÁSTICA ARTÍSTICA: A PERSPECTIVA DE PRATICANTES INICIANTES
}

\author{
Vitor Ricci Costa \\ Universidade de São Paulo, Ribeirão Preto, São Paulo, Brasil \\ Maurício dos Santos Oliveira \\ Universidade Federal do Espírito Santo, Vitória, Espírito Santo, Brasil \\ Michele Viviene Carbinatto \\ Universidade de São Paulo, Ribeirão Preto, São Paulo, Brasil \\ Myrian Nunomura \\ Universidade de São Paulo, Ribeirão Preto, São Paulo, Brasil
}

\begin{abstract}
Resumo
O objetivo do presente estudo foi identificar os fatores que motivaram as crianças a iniciar a prática de GA. Entrevistamos ginastas iniciantes de ambos os sexos, com idades entre 7 e 10 anos. Os dados foram coletados por meio de entrevistas semiestruturadas e, para o seu tratamento, recorremos à técnica de "análise de conteúdo". Os resultados revelaram que tanto motivos intrínsecos quanto extrínsecos atraíram os ginastas iniciantes para a modalidade. Contudo, observamos que os fatores extrínsecos exercem maior impacto, principalmente, devido à influência social da família e dos treinadores. Entendemos que os resultados podem indicar caminhos para a atuação dos treinadores nesse estágio da formação esportiva e assim potencializar a adesão dos praticantes à Ginástica Artística.
\end{abstract}

Palavras-chave: Ginástica Artística. Motivação. Pedagogia do Esporte.

\section{Introdução}

Malina (2016) destaca que o número de crianças e jovens envolvidos com a prática esportiva cresce progressivamente e de forma significativa. Muitos iniciam a prática com o objetivo de alcançar o alto rendimento. No entanto, o autor ressalta que, embora o número de crianças e jovens envolvidos com o esporte seja elevado, serão poucos aqueles que chegarão ao alto rendimento esportivo (MALINA, 2016).

Para atingir o alto rendimento, é sabido que há necessidade de muitos anos de dedicação intensa (MARTINDALE; COLLINS; DAUBNEY, 2005; VAYENS, 2008, 2009). Entretanto, há indivíduos que se envolvem na prática esportiva por outras razões. Dessa forma, é essencial que o treinador atente não somente para aqueles que buscam ascender ao alto rendimento, mas que compreenda e considere a individualidade e as pretensões dos demais praticantes no processo de formação esportiva.

Tanto na literatura específica quanto entre os profissionais atuantes nesse contexto discutem-se os fatores que motivariam as crianças e os jovens à prática esportiva (FARROW; BARKER; MACMAHON, 2008; ARMOUR, 2013; KEEGAN et al., 2014). Conforme Weinberg e Gould (2008), a motivação é um conceito geral utilizado para compreender o processo 
complexo que orienta e coordena a direção e a intensidade de esforço dos indivíduos. Os autores explicam que a direção do esforço refere-se à busca de algo e a intensidade, ao esforço durante a ação.

A motivação é essencial para o início da prática esportiva. Weinberg e Gould (2008) sugerem que a escolha por determinada modalidade depende de fatores pessoais (necessidades, interesses, objetivos, personalidade) e fatores situacionais (estilo de liderança do treinador, facilidades de acesso à prática, atividades atrativas, desafios, influências sociais).

Weiss e Petlichkoff (1989) elencam que os aspectos motivacionais para iniciar e permanecer na prática de esportes estariam relacionados à diversão, ao desejo de aprender novas habilidades, à vivência e à superação de desafios e ao relacionamento social. Apesar dos aspectos positivos e benéficos da participação em esportes, Scalon (2004) destaca que muitas crianças e jovens perdem o interesse pela prática e, após determinado tempo, abandonam as atividades.

Assim, um dos caminhos para tentar evitar o abandono precoce da prática esportiva seria o treinador atuar fundamentado na compreensão dos fatores motivacionais e de suas consequências.

Ao analisarem o contexto da Ginástica Artística (GA), Massimo e Massimo (2013) citam que muitos treinadores intervêm num nível intuitivo nos aspectos psicológicos da formação esportiva. No entanto, é necessário que eles busquem e tenham acesso aos conhecimentos dessa área, que inclui a motivação, para que estejam cientes de "por que" e de "como" agir, a fim de auxiliar os ginastas em sua trajetória atlética.

A investigação em campo e a compreensão sobre a realidade do cotidiano da modalidade e de seus protagonistas, ou seja, quem vive, faz e se dedica ao esporte, poderia evidenciar fragilidades que necessitam ser repensadas à luz da Pedagogia do Esporte.

Assim, o objetivo do presente estudo foi identificar os fatores que motivaram as crianças a iniciar a prática de GA. A partir desses dados, esperamos incitar a reflexão e a posterior compreensão de treinadores sobre os fatores motivacionais de seus praticantes para que atuem em favor do sucesso na formação esportiva.

\section{Procedimentos metodológicos}

Para identificar e discutir os fatores que motivaram as crianças a iniciarem a prática de GA, utilizamos a entrevista semiestruturada que, segundo Amado (2014), consiste em um plano prévio de questionamentos para nortear aquilo que o entrevistador julga essencial obter, em ordem lógica, mas que permite grande liberdade de interação com o entrevistado.

Foram entrevistadas 22 crianças com idades entre 7 e 10 anos, sendo 18 do sexo feminino e 4 do sexo masculino, todas iniciantes na GA e praticantes há menos de um ano.

Os locais de prática se restringiram às academias privadas e aos centros públicos localizados nos municípios de Descalvado e de São Carlos, no interior do estado de São Paulo. Essa decisão apoiou-se na disponibilidade e na localização dos colaboradores. Assim, o número de praticantes entrevistados foi suficiente para representar o contexto dos dois locais de prática. Não foi utilizado critério de saturação.

Para o tratamento dos dados, empregamos a técnica de análise de conteúdo proposta por Bardin (2010). Trata-se de uma técnica de organização e redução dos dados que utiliza procedimentos sistemáticos e objetivos de descrição do conteúdo das mensagens. Nessa técnica, os dados são codificados, classificados e categorizados, tornando-se possível a análise sobre as mensagens que emergem do conteúdo das entrevistas e que se referem aos pontos de interesse para a pesquisa.

Antes da coleta, os entrevistados foram esclarecidos sobre os procedimentos da pesquisa e, para cada um deles, foi entregue um Termo de Consentimento Livre e Esclarecido, o 
qual foi assinado pelos responsáveis legais. O projeto foi aprovado pelo Comitê de Ética em Pesquisa da Faculdade de Filosofia, Ciências e Letras de Ribeirão Preto - Universidade de São Paulo (FFCLRP-USP) (Processo CAAE nº 22136013.5.0000.5407).

\section{Resultados}

Os depoimentos dos ginastas revelaram fatores de origem intrínseca e extrínseca que incidem na motivação para o início da prática de GA, conforme Figura 1.

Optamos por discutir os dados em suas respectivas subcategorias: motivação intrínseca e motivação extrínseca. Ademais, devido ao volume de respostas, elegemos apenas algumas unidades de contexto que melhor sintetizam as unidades de registro.

Figura 1 - A motivação para o início da prática de GA

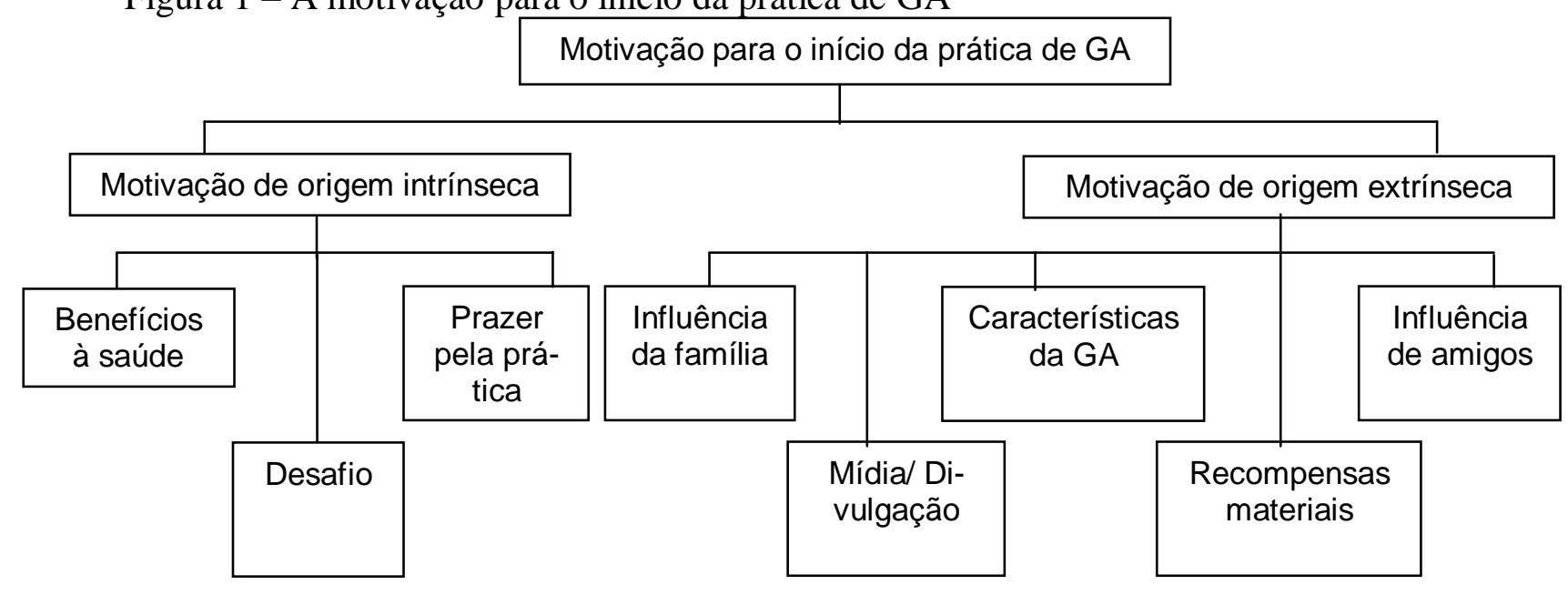

Fonte: Elaborado pelo autor.

\section{Discussão}

\section{Motivação intrínseca}

A motivação intrínseca é apontada como a propensão inata de cada indivíduo e está relacionada ao interesse espontâneo em realizar determinada tarefa (DECI; RYAN, 1985; RYAN; DECI, 2000).

As pessoas intrinsecamente motivadas se esforçam internamente para serem competentes e autodeterminadas, a fim de dominar a tarefa proposta. Elas participam por amor ao esporte ou jogam por orgulho, apreciam a competição, gostam de ação e ativação, mantêm foco no divertimento e querem aprender o máximo de habilidades possíveis (WEINBERG; GOULD, 2008).

\section{Prazer pela prática}

Cumming (2012) cita que atletas intrinsecamente motivados buscam na prática esportiva o prazer e a satisfação, aspectos que estão vinculados ao processo de aprendizagem, exploração e compreensão. Alguns relatos expõem as unidades de contexto relacionadas ao pra- 
zer pela prática relatado pelas crianças: "tudo o que eu quero fazer é ginástica" (G18); "Eu faço porque eu amo ginástica, eu adoro praticar ela" (G16).

Cogan e Vidmar (2000) ponderam que muitos ginastas enveredam pelo universo da GA pelo divertimento proporcionado na execução dos elementos e pelas experiências motoras que os aparelhos proporcionam, como a sensação de voar. Além disso, o sentimento de realização, ao aprender um novo elemento, e a possibilidade de fazer amigos poderiam relacionarse ao prazer e se tornariam fontes de motivação.

\section{Benefícios da prática à saúde}

Vallerand (2007) sintetiza que, na motivação intrínseca, o indivíduo se engaja na atividade para o seu próprio bem. Isso explica a emergência de relatos que contemplam o ato de se beneficiar com a prática da GA, por exemplo, a saúde, conforme as seguintes unidades de contexto: "É bom para minha saúde" (praticar GA) (G2); "assim porque eu queria emagrecer, porque eu posso tá em risco de diabetes" (G3).

Ao analisarem a natureza da GA, Nunomura et al. (2009) citam que ela tem potencial para favorecer o processo de crescimento e desenvolvimento de seus praticantes, assim como permite o aprimoramento dos indivíduos no âmbito social e psicológico. Essas características incidem na saúde de seus praticantes em perspectiva global sobre o bem-estar físico, social e psicológico.

\section{Desafio}

Vallerand (2007) expõe que os indivíduos buscam nas atividades a sensação de tentar e conquistar algo, criar alguma coisa ou superar a si mesmo.

Nesse sentido, observamos que alguns ginastas buscam na GA o desafio e a possibilidade de se superar: "Vai me motivar porque daí eu vou fazendo e aprendendo a fazer direito, daí eu vou gostar" (exercícios difíceis) (G13); “Não, quando eu erro eu falo, eu vou conseguir fazer" (G22).

Segundo Nunomura et al. (2009), a GA possibilita aos seus praticantes oportunidade para superar obstáculos, os quais permitem lidar com emoções e situações que requerem a resolução de problemas, fato que reforça a autoestima e também contribui na formação humana.

\section{Motivação extrínseca}

Ryan e Deci (2000) sintetizam que a motivação extrínseca pode ser identificada quando o motivo que impulsiona o indivíduo à determinada ação está relacionado ao reconhecimento ou a recompensas e influências externas.

\section{Influência da família}


Nunomura e Oliveira (2014) expõe que, na GA, os pais são os responsáveis por fornecer subsídios para que os ginastas iniciem seus primeiros saltos na modalidade e se mantenham na prática. Ainda, Baxter-Jones e Mafulli (2003) pontuam que uma parcela pronunciada de ginastas atribui aos pais a sua inserção na modalidade. Os depoimentos a seguir constatam o fato: "Na verdade não fui eu, quando eu era pequena eu era muito espoleta, eu pulava muito e minha mãe decidiu me colocar na ginástica" (G11); "daí a minha mãe e meu pai eles foram falando, você não quer fazer ginástica?" (G20); "Os meus pais viram essa academia e gostaram e me incentivaram a participar" (G15).

Nakashima, Nascimento Junior e Vieira (2012) afirmam que certas crenças e costumes da sociedade são transmitidos de pai para filho. Os pais-atletas geralmente apoiam muito os filhos para que se tornem atletas também, conforme relato a seguir: "Ah... eles também gostam, minha mãe falou pra eu fazer ginástica porque ela também gosta bastante e, quando ela era pequena, ela treinava ginástica também, daí ela contou tudo pra mim que ela fazia na ginástica, daí eu comecei a gostar do que ela falou pra mim e escolhi a ginástica" (G2).

Outro fator que despertou nossa atenção é o modelo de irmãos mais velhos revelado por Carbinatto et al. (2010). Identificamos que os irmãos costumam despertar a curiosidade das crianças, pois estas desejam descobrir o que aqueles fazem na prática da GA. Assim, há influência do núcleo familiar, conforme o depoimento a seguir: "A GA é porque meu irmão, ele fazia estrela, ele não fazia GA, mas sabia virar estrela, dar cambalhota e essas coisas, daí todo mundo falava que ele tinha que fazer GA, daí ele começou a fazer GA e eu quis fazer também" (G21).

Esses resultados coincidem com os dados de Vilani e Samulski (2002), os quais sintetizam que os indivíduos iniciam práticas e adquirem certos comportamentos e características a partir de inter-relações presentes no seu meio social. Assim, a família será o ambiente social primário, no qual essas inter-relações iniciarão.

\section{Mídia/divulgação}

Os estudos sobre o impacto da mídia nas escolhas das pessoas têm crescido consideravelmente e no esporte não é diferente. A alta exposição de determinadas modalidades na rede televisiva e a criação de um imaginário social sobre os atletas como "heróis" influenciam na motivação e na escolha do esporte. Também pode incidir na motivação, pois criaria um espetáculo em torno do jogo e/ou do campeonato (BETTI, 1998; BOARDLEY, 2013).

Constatamos que grande parte dos entrevistados mencionou a influência da mídia para iniciar a prática da modalidade: "Eu vi um atleta fazendo ginástica artística e eu quis praticar" (G5); “Ah, sim, eu tenho TV por assinatura. Eu assisto esporte, de ginástica” (G6); "Sim, tava na época da Olimpíada e eu vi muitas pessoas fazendo saltos e um monte de coisa" (G3).

Observamos que a divulgação nas escolas poderia incidir na escolha das crianças em prol da prática esportiva: "daí ano passado o Marquinho (treinador) levou a ficha na escola e eu escolhi ginástica" (G6).

Ressaltamos que a renomada ginasta Nadia Comaneci foi detectada no ambiente escolar pelo treinador Bela Karolyi (1994). O fato nos faz refletir sobre a importância da divulgação da modalidade nesse ambiente, a fim de ampliar o número de adeptos e atrair as crianças.

Características da Ginástica Artística (GA) 
A presença de aparelhos de grande porte, elementos acrobáticos e movimentos diferenciados que instigam o potencial do praticante chamam a atenção e, consequentemente, causam admiração. Nunomura et al. (2009, p. 202) destacam que "a GA inclui uma variedade de aparelhos, cada um com suas particularidades, que proporcionam ao praticante um amplo conhecimento e desenvolvimento de práticas corporais".

Nessa perspectiva, Cogan e Vidmar (2000) afirmam que grande parte dos ginastas inicia na modalidade pela diversão que ela proporciona, devido a sua singularidade. Segundo os autores, os ginastas se apaixonam pela sensação propiciada pelos movimentos, a oportunidade de se lançar ao ar e a percepção de domínio do corpo.

Os dados coletados revelaram que a plasticidade e a expressividade da GA incidiram na motivação dos ginastas. Comprovamos que os exercícios e os aparelhos da modalidade causam muita excitação nas crianças, conforme os seguintes relatos: "Eu gosto de fazer parada de mão, pular na cama elástica, fazer um monte de coisa, o que eu não gosto? nada" (G1); "Eu gosto dos aparelhos" (G3); "porque antes, quando eu não fazia ginástica, eu gostava de fazer estrela, várias coisas, eu gostava de ficar fazendo" (G20); "Eu gosto bastante dos exercícios que a ginástica tem, de virar estrela, cambalhota, andar na trave" (G15).

Os depoimentos dos ginastas reforçam a perspectiva de Sands e Conklin (1984) de que, desde a década de 1980, o poder da arte, da beleza e das habilidades das ginastas era atraente para as novas gerações.

Assim, ao explorar a diversidade de aparelhos e movimentos da GA, associados a propostas lúdicas, permitiríamos que o aprendizado pela diversão contribuísse para um ambiente prazeroso e favorável ao ensino. Ainda, o potencial das crianças poderia ser desenvolvido, o que também auxiliaria na manutenção da motivação para a prática de GA.

\section{Influência dos amigos}

A possibilidade de interagir com o grupo de amigos é uma das razões importantes para a prática esportiva entre os jovens (DOUGE, 1999). Ryan e Deci (2000) sintetizam que um dos principais motivos de predisposição das pessoas para realizar determinadas ações relaciona-se ao sentimento de valorização por indivíduos que exercem influências preponderantes em suas vidas. O meio social exerce influência significativa na escolha dos indivíduos.

No presente estudo, observamos que as amizades apoiaram o início da prática de alguns sujeitos: "Porque, quando eu comecei, a minha amiga fazia, aí eu quis fazer também" (G13); "Eu achei as meninas fazendo lá, eu achei legal, daí eu quis fazer também, aprender o que elas aprendiam" (G14). Assim, esses depoimentos confirmam a teoria - possivelmente, os laços de amizade colaborariam na permanência na GA. Portanto, o treinador deve considerar a influência dos amigos, identificar e nutrir as afinidades entre os colegas de prática, o que contribuiria para ensinar a importância da cooperação e do trabalho em equipe, que também foi apontado pelas crianças: "Tenho bastante (amigos), elas dão bastante força também, às vezes, quando eu vou fazer algum movimento, daí eu erro, elas também me dão bastante força" (G12); "Tem uma amiga minha que fala pra mim continuar vindo, pra gente continuar fazendo exercícios juntas" (G14).

\section{Recompensas materiais}

Nunomura e Oliveira (2014) afirmam que, na GA brasileira, o reconhecimento de mérito por compensação financeira é recente. Os autores citam que a mídia reforça, muitas vezes, que o retorno financeiro com a prática esportiva seja possível, o que incentivaria o envolvimento no esporte e geraria a expectativa de ascender socialmente. No presente estudo, confirmamos essa expectativa entre as crianças com a prática da GA: "Eu gostaria de ganhar coi- 
sa, porque meu pai e minha mãe não têm muito dinheiro, por isso que a gente não pode comprar muitas coisas e se nós ganhar aqui né” (G9).

As recompensas podem ser um fator motivacional relevante para o início da prática. Entretanto, Weinberg e Gould (2008) afirmam que os indivíduos que iniciam no esporte em busca de recompensas desistiriam facilmente dessa prática.

\section{Considerações finais}

Concluímos que os motivos de origem extrínseca têm impacto maior sobre o início da prática entre os ginastas, o que é explicado pelo fato de as crianças serem altamente influenciadas pelo meio social ao qual pertencem. Assim, o treinador deveria estar atento aos aspectos relacionados à motivação de origem extrínseca.

A relação treinador-pais tem consequências na motivação das crianças e no processo de formação esportiva. Portanto, o treinador deve atuar em favor da participação ativa dos pais na prática esportiva dos filhos e explicar a eles sobre a importância do papel que eles exercem no processo de formação esportiva das crianças. $O$ treinador deveria manter comunicação aberta e ressaltar seus objetivos, reforçar que a presença dos pais no ginásio, nos festivais e nas competições é importante, pois motiva as crianças e, sobretudo, demonstra interesse, aprovação e respeito pela escolha delas.

A aproximação do treinador com os pais é oportuna para explicar que o ensino e o aprendizado na GA são fruto de vários anos de investimento e eles, pais, devem acompanhar e apoiar todas as fases. No entanto, é preciso manter o equilíbrio no envolvimento dos familiares, haja vista que o excesso desse envolvimento poderia acarretar cobrança e pressão por resultados, o que comprometeria o aprendizado dos jovens ginastas e o trabalho do treinador (NUNOMURA; OLIVEIRA, 2014).

Como os amigos revelaram-se influenciadores na motivação para o início da prática de GA, o treinador poderia desenvolver estratégias que potencializem essa influência positiva, como: incentivar os praticantes a levar colegas para conhecer a GA; propor atividades que reforcem o companheirismo e a cooperação entre os praticantes; promover momentos de lazer entre os colegas da GA; aproveitar dias festivos para promover aulas temáticas preparadas com o auxílio de todos; promover encontro/confraternização entre praticantes de instituições distintas.

Ponderamos também que é papel dos treinadores desassociar as recompensas, oriundas da prática esportiva, de prêmios exclusivamente materiais. Devemos conscientizar os jovens atletas sobre os prêmios vinculados ao bem-estar físico, social e emocional que constituem os principais lauréis do esporte. Ademais, por vezes é necessário orientar as expectativas das crianças em relação aos resultados, para que essa motivação orientada a um objetivo não se torne um fator de estresse em razão de cobranças ou pressões.

Ressaltamos que o treinador deveria trabalhar as aspirações e as expectativas em relação aos campeonatos, para que as crianças não se frustrem com as derrotas, a ponto de abdicarem da prática da GA. Este deve conscientizar os praticantes que o objetivo nas competições não é só ganhar medalhas, mas fazê-los perceber o seu crescimento no processo de formação esportiva. Assim, o treinador deveria reforçar os valores atribuídos à prática, cultivar o espírito esportivo, valorizar a participação e a oportunidade das crianças demonstrarem suas habilidades em competições e festivais e o fato de construir novas amizades.

Por vezes, estudos preliminares (DOUGE, 1999; LOPES; NUNOMURA, 2007; NUNOMURA; OKADE; CARRARA, 2009; MCLEAN; MALLETT, 2012) e também o presente estudo revelaram que a falta de conhecimento das motivações iniciais que atraíram os praticantes e o descompasso entre os objetivos do treinador, dos pais e das crianças comprometeriam o interesse pela prática esportiva e, não raras vezes, culminariam no seu abandono. 
Assim, consideramos que, quando os treinadores estão cientes dos fatores que incentivam o início da prática esportiva, ou seja, da motivação intrínseca e extrínseca, eles têm em mãos ferramentas potenciais para intervir no engajamento progressivo e no atendimento dos anseios dos praticantes.

\title{
THE MOTIVATION FOR THE FIRST "UPS AND DOWNS" IN ARTISTIC GYM- NASTICS: BEGGINERS' PERSPECTIVE
}

\begin{abstract}
This study aimed to identify children's motivation to start in Artistic Gymnastics (AG) practice. The participants of this study were novice gymnasts, boys and girls, aged between 7 and 10 years. The data were collected through semi-structured interview and for the data treatment we used the "Content Analysis" proposed by Bardin (2010). The results showed that novice gymnasts were influenced by both intrinsic and extrinsic motivation. However, we notice that the extrinsic factors have more impact on the gymnasts, mainly due to the social influence of the family and coaches. We believe that the outcomes of this study may indicate ways for the coaches' intervention at this stage of athlete development and thus enhance the engagement of these young gymnasts in AG.
\end{abstract}

Keywords: Artistic Gymnastics. Motivation. Sport Pedagogy.

\section{LA MOTIVACIÓN PARA LAS PRIMERAS AVENTURAS EN GIMNASIA ARTÍS- TICA: LA PERSPECTIVA DE PRACTICANTES PRINCIPIANTES}

\section{Resumen}

El objetivo del presente estudio fue identificar los factores que motivaron a los niños a iniciar la práctica de Gimnasia Artística (GA). Entrevistamos gimnastas principiantes de ambos sexos, con edades entre 7 y 10 años. Los datos fueron recogidos a través de entrevistas semiestructuradas y, para su tratamiento, utilizamos a la técnica de "Análisis de Contenido". Los resultados indicaron que, tanto motivos intrínsecos como extrínsecos atrajeron a los gimnastas principiantes para la modalidad. Sin embargo, observamos que los factores extrínsecos ejercen mayor impacto principalmente debido a la influencia social de la familia y de los entrenadores. Entendemos que los resultados pueden indicar caminos para la actuación de los entrenadores en esta fase inicial de la formación deportiva y, de esta forma, fomentar la adhesión de los practicantes a la Gimnasia Artística.

Palabras clave: Gimnasia Artística. Motivación. Pedagogía del Deporte.

\section{Referências}

AMADO, J. (Ed.) Manual de investigação qualitativa em educação. Coimbra: Coimbra University Press, 2014.

ARMOUR, K. (Ed.). Sport pedagogy: an introduction for teaching and coaching. New York: Routledge, 2013.

BARDIN, L. Análise de conteúdo. Lisboa: Edições 70, 2010. 
BAXTER-JONES, A. D.; MAFULLI, N. Parental influence on sport participation in elite young athletes. Journal of Sports Medicine and Physical Fitness, Torino, v.43, n.2, p. 250255, 2003.

BETTI, M. A. Janela de vidro: esporte, televisão e Educação Física. Campinas: Papirus, 1998.

BOARDLEY, I. D. Can viewing London 2012 influence sport participation? A viewpoint based on relevant theory. International Journal of Sport Policy, London, v. 5, n. 2, p. 245 257, 2013.

CARBINATTO, M. V. et al. Motivação e Ginástica Artística no contexto extracurricular. Revista Conexões, Campinas, v. 8, n. 3, p. 124-145, 2010.

COGAN, K. D; VIDMAR, P. Sports psychology library: gymnastics. Morgantown: Fitness Information Technology, 2000.

CUMMING, S. Motivation - intrinsec and extrinsec. In: BARTLETT, R.; Gratton, C.; ROLF, C. (Org.). Encyclopedia of international sports studies. London: Routledge, 2012. p. 831-833.

DECI, E.; RYAN, R. M. Intrinsic motivation and self-determination in human behavior. New York: Plenum, 1985.

DOUGE, B. Progressão das actividades não competitivas para as competitivas. Revista Treino Desportivo, Lisboa, v. 8, n. 1, p. 6-8, 1999.

FARROW, D.; BARKER, J.; MACMAHON, C. (Ed.). Developing sport expertise: researchers and coaches out theory into practice. New York: Routledge; 2008.

KAROLYI, B.; RICHARDSON, N. A. Feel no fear: the power, passion, and politics of a life in gymnastics. Nova York: Hyperion, 1994.

KEEGAN, R. et al. A qualitative investigation of the motivational climate in the elite sport. Psychology of Sport and Exercise, Champaign, v. 15, n. 1, p. 97-107, 2014.

LOPES, P.; NUNOMURA, M. Motivação para a prática e permanência na ginástica artística de alto nível. Revista Brasileira de Educação Física e Esporte, São Paulo, v. 21, n. 3, p. 177-187, 2007.

MALINA, R. M. Organized youth sports: background, trends, benefits and risks. In:

COELHO, M. J. et al. (Org.). Youth sports: participation, trainability and readiness. Coimbra: Coimbra University Press, 2016. p. 2-27.

MARTINDALE, R. J. J.; COLLINS, D.; DAUBNEY, J. Talent development: a guide for practice and research within sport. Quest, London, v. 57, n. 4, p. 353-375, 2005. 
MASSIMO, J.; MASSIMO S. (Ed.). Gymnastics psychology: the ultimate reference guide for coaches, athletics and parents. Nova York: Morgan James Publishing, 2013.

MCLEAN, K. N.; MALLET, C. J. What motivate the motivators? An examination of sport coaches. Physical Education and Sport Pedagogy, London, v. 17, n. 1, p. 21-35, 2012.

NAKASHIMA, F. S.; NASCIMENTO JUNIOR, J. R. A.; VIEIRA, L. F. O papel dos pais na trajetória de atletas de ginástica rítmica. Pensar a Prática, Goiânia, v. 15, n. 4, p. 821-1113, 2012.

NUNOMURA, M. et al. Fundamentos da Ginástica Artística. In: NUNOMURA, M.; TSUKAMOTO, M. H. C. (Org.). Fundamentos das ginásticas. Jundiai: Fontoura, 2009. p. 201239.

NUNOMURA, M.; OKADE, Y.; CARRARA, P. How Much Artistic Gymnastics coaches know about their gymnasts motivation. Science of Gymnastics Journal, Ljubljana, v. 4, n. 2, p. 27-37, 2009.

NUNOMURA, M.; OLIVEIRA, M. S. A participação dos pais na carreira das atletas femininas de ginástica artística: a perspectiva dos técnicos. Revista Brasileira de Educação Física e Esporte, São Paulo, v. 28, n. 1, p. 125-134, 2014.

RYAN, R. M.; DECI, E. L. Self-determination theory and the facilitation of intrinsic motivation, social development, and well-being. American psychologist, Rochester, v. 55, n. 1, p. 68-78, 2000.

SANDS, W. A.; CONKLIN, S. Everybody's gymnastics book. New York: Scribner's and Sons, 1984.

SCALON, R. M (Ed.) A psicologia do esporte e a criança. Porto Alegre: EDIPUCRS, 2004.

VALLERAND, R. J. Intrinsic and extrinsic motivation in sport and physical activity: a review and a look at the future. In: TENENBAUM, G.; EKLUND, E. (Ed.). Handbook of sport psychology. New York: John Wiley, 2007. p. 49-83.

VAYENS, R. et al. Talent Identification and development programmes in sport: current models and future directions. Sports Medicine, Auckland, v. 38, n. 9, p. 703-714, 2008.

VAYENS, R. et al. Talent identification and promotion programmes of olympic athletes. Journal of Sport Sciences. London, v. 27, n. 13, p. 1367-1380, 2009.

VILANI, L. H. P.; SAMULSKI, D. Família e esporte: uma revisão sobre a influência dos pais na carreira esportiva de crianças e adolescentes. In: SILAMI GARCIA, E.; LEMOS, K. L. M. (Org.). Temas atuais VII: Educação Física e esportes. Belo Horizonte: Editora Health, 2002. p. 09-26.

WEINBERG, R.; GOULD, D. (Ed.). Fundamentos da psicologia do esporte e do exercício. Porto Alegre: Artmed, 2008. 
WEISS, M. R.; PETLICHKOFF, L. M. Children's motivation for participation in and withdrawal from sport: identifying the missing links. Pediatric Exercise Science, Champaign, v. 1, n. 3, p. 195-211, 1989.

\section{Agradecimentos}

Os autores agradecem o apoio da Pró-Reitoria de Pesquisa da Universidade de São Paulo.

Recebido em: 06/10/2016

Revisado em: 08/02/2017

Aprovado em: 05/04/2017

Endereço para correspondência:

vitor.costabr@gmail.com

Vitor Ricci Costa

Universidade de São Paulo

Av. Bandeirantes, 3.900

Monte Alegre

Ribeirão Preto - SP

CEP: $14040-900$ 